\title{
Association of Left Atrial Size Measured by Non-Contrast Computed Tomography with Cardiovascular Risk Factors-The Danish Cardiovascular Screening Trial (DANCAVAS)
}

\author{
Maise Høigaard Fredgart ${ }^{1,2}$, Jes Sanddal Lindholt ${ }^{3,4,5}$, Axel Brandes ${ }^{1}{ }^{\mathbb{D}}$, Flemming Hald Steffensen ${ }^{6} \mathbb{D}$, \\ Lars Frost ${ }^{7}{ }^{(D}$, Jess Lambrechtsen ${ }^{8}$, Marek Karon ${ }^{9}$, Martin Busk ${ }^{6}$, Grazina Urbonaviciene ${ }^{7}$, Kenneth Egstrup ${ }^{8}$, \\ Lida Khurrami ${ }^{1}$, Oke Gerke ${ }^{10}$ and Axel Cosmus Pyndt Diederichsen $1,5, * \mathbb{D}$
}

Citation: Fredgart, M.H.; Lindholt, J.S.; Brandes, A.; Steffensen, F.H.; Frost, L.; Lambrechtsen, J.; Karon, M.; Busk, M.; Urbonaviciene, G.; Egstrup, K.; et al. Association of Left Atrial Size Measured by Non-Contrast Computed Tomography with Cardiovascular Risk Factors-The Danish Cardiovascular Screening Trial (DANCAVAS). Diagnostics 2022, 12, 244. https:// doi.org/10.3390/diagnostics12020244

Academic Editor: Damiano Caruso

Received: 3 January 2022

Accepted: 18 January 2022

Published: 19 January 2022

Publisher's Note: MDPI stays neutral with regard to jurisdictional claims in published maps and institutional affiliations.

Copyright: (C) 2022 by the authors. Licensee MDPI, Basel, Switzerland. This article is an open access article distributed under the terms and conditions of the Creative Commons Attribution (CC BY) license (https:// creativecommons.org/licenses/by/ $4.0 /)$.
1 Department of Cardiology, Odense University Hospital, 5000 Odense, Denmark; Maise.Hoigaard.Fredgart@rsyd.dk (M.H.F.); axel.brandes@rsyd.dk (A.B.); Lida.Khurrami2@rsyd.dk (L.K.)

2 Odense Patient Data Explorative Network (OPEN), Odense University Hospital, 5000 Odense, Denmark

3 Department of Cardiothoracic and Vascular Surgery, Odense University Hospital, 5000 Odense, Denmark; Jes.Sanddal.Lindholt@rsyd.dk

4 Cardiovascular Centre of Excellence (CAVAC), Odense University Hospital, 5000 Odense, Denmark

5 Elitary Research Centre of Individualised Medicine in Arterial Disease, Odense University Hospital, 5000 Odense, Denmark

6 Department of Cardiology, Hospital Lillebælt, 7100 Vejle, Denmark; Flemming.Hald@rsyd.dk (F.H.S.); Martin.Busk@rsyd.dk (M.B.)

7 Department of Cardiology, Regional Hospital Central Jutland, 8600 Silkeborg, Denmark; larfrost@rm.dk (L.F.); grazina.urbonaviciene@viborg.rm.dk (G.U.)

8 Department of Cardiology, Svendborg Hospital, 5700 Svendborg, Denmark; jess.lambrechtsen@rsyd.dk (J.L.); Kenneth.Egstrup@rsyd.dk (K.E.)

9 Department of Medicine, Nykøbing Falster Hospital, 4800 Nykøbing Falster, Denmark; mkar@regionsjaelland.dk

10 Department of Nuclear Medicine, Odense University Hospital, 5000 Odense, Denmark; oke.gerke@rsyd.dk

* Correspondence: Axel.Diederichsen@rsyd.dk

\begin{abstract}
Left atrium (LA) size is associated with adverse cardiovascular events. The purpose of this study was to investigate the association of LA enlargement measured by non-contrast CT (NCCT) with traditional cardiovascular risk factors. Individuals aged 60-75 years from the populationbased multicentre Danish Cardiovascular Screening (DANCAVAS) trial were included in this crosssectional study. The LA was manually traced on the NCCT scans, and the largest cross-section area was indexed to body surface area. All traditional risk factors were recorded, and a subgroup received an echocardiographic examination. We enrolled 14,987 individuals. Participants with known cardiovascular disease or lacking measurements of LA size or body surface area were excluded, resulting in 10,902 men for the main analysis and 616 women for a sensitivity analysis. Adjusted multivariable analysis showed a significantly increased indexed LA size by increasing age and pulse pressure, while smoking, $\mathrm{HbA} 1 \mathrm{c}$, and total cholesterol were associated with decreased indexed LA size. The findings were confirmed in a supplementary analysis including left ventricle ejection fraction and mass. In this population-based cohort of elderly men, an association was found between age and pulse pressure and increasing LA size. Surprisingly, smoking, $\mathrm{HbA1c}$, and total cholesterol were associated with a decrease in LA size. This indicates that the pathophysiology behind atrial cardiomyopathy is not only reflected by enlargement, but also shrinking.
\end{abstract}

Keywords: left atrial size; non-contrast computed tomography; echocardiography; cardiovascular risk factors

\section{Introduction}

Left atrial (LA) size is associated with adverse cardiovascular events and has been recognised to be an independent predictor of cardiovascular outcome [1-4]. As an increased LA size is connected to the risk of atrial fibrillation and heart failure, the risk factors causing 
LA dilation would therefore be expected to be similar to those leading to atrial fibrillation and heart failure. Hypertension and obesity are some of the most important modifiable risk factors for atrial fibrillation; in addition, diabetes, obstructive sleep apnoea, smoking and alcohol use are also known to increase the risk of atrial fibrillation [5]. However, atrial cardiomyopathy is not only reflected by dilatation, but also fibrosis, contractile dysfunction, and arrhythmias. Thus, examining associations between LA size and risk factors could improve our understanding of mechanisms behind atrial cardiomyopathy.

An increasing number of patients are examined by cardiac non-contrast computed tomography (NCCT) to evaluate coronary artery calcium (CAC) score, as this is the most important risk marker of cardiovascular disease [6,7]. We recently performed approximately 15,000 NCCT scans in the population-based Danish Cardiovascular Screening (DANCAVAS) trial to evaluate the benefit of a cardiovascular screening [8]. As these NCCT scans are appropriate for measurements of LA size, we aimed with this study to evaluate associations between the risk factors and LA size in the DANCAVAS population.

\section{Materials and Methods}

\subsection{Study Population}

Participants in this cross-sectional study were recruited from the DANCAVAS trial [8]. The study began in September 2014. Both men and woman were invited in the beginning, but as a pilot study concluded that women were not likely to benefit cost-effectively, only men were recruited from May 2015 [9]. All men aged 60-75 years living on the Island of Funen and the surrounding communities of Vejle, Silkeborg and Nykøbing Falster were identified and randomly invited for the cardiovascular screening program. The screening program included a low-dose NCCT scan, among other things. In this substudy, we excluded participants without an LA size measurement, missing body surface area (BSA), and/or with known cardiovascular disease (prior myocardial infarction, coronary revascularisation, stroke, atrial fibrillation and surgical intervention for valvular heart disease, aortic aneurysm or peripheral arterial disease).

Study data were collected and managed using REDCap data management, hosted at the Odense Patient data Explorative Network. The study was registered at http:/ / www. isrctn.com/ (ISRCTN12157806).

\subsection{Non-Contrast Cardiac Computed Tomography}

Various CT scanners were used. Two centres used a Siemens Flash (Gantry rotation time $0.28 \mathrm{~s}, 3.0 \mathrm{~mm}$ collimation, acquisition $128 \times 0.6 \mathrm{~mm}, 120 \mathrm{kV}$ tube voltage, $90 \mathrm{mAs}$ tube current) or Siemens Force (Gantry rotation time $0.25 \mathrm{~s}, 3.0 \mathrm{~mm}$ collimation, acquisition $38 \times 1.2 \mathrm{~mm}, 120 \mathrm{kV}$ tube voltage, $80 \mathrm{mAs}$ tube current) (Siemens Healthcare Solutions, Erlangen, Germany). Imaging was prospectively ECG-triggered at 70\% of the R-R interval if the heart rate was $<75 \mathrm{bpm}$ or at $250 \mathrm{~ms}$ after the QRS-complex if heart rate was $>75 \mathrm{bpm}$ for the Siemens Flash, and at 70\% of the R-R interval if heart rate was $<75 \mathrm{bpm}$ or at $300 \mathrm{~ms}$ after the QRS-complex if heart rate was $>75 \mathrm{bpm}$ for the Siemens Force. A third centre used a Philips iCT 256 slice scanner (Gantry rotation time $0.27 \mathrm{~s}, 2.5 \mathrm{~mm}$ collimation, auto acquisition $128 \times 0.625,112 \times 0.625$ or $96 \times 0.625 \mathrm{~mm}, 120 \mathrm{kV}$ tube voltage, $50 \mathrm{mAs}$ tube current) (Phillips, Amsterdam, Holland). Imaging was prospectively ECG-triggered at $75 \%$ of the R-R interval at all heart rates. A fourth centre used a Toshiba Aquilion One 320 slice scanner (Gantry rotation time $0.35 \mathrm{~s}$, acquisition collimation $320 \times 0.5 \mathrm{~mm}, 120 \mathrm{kV}$ tube voltage, $28 \mathrm{mAs}$ tube current) (Toshiba, Tokyo, Japan). Imaging was prospectively ECG-triggered at $75 \%$, exposure window $450 \mathrm{~ms}$, if the heart rate was $<65 \mathrm{bpm}$ or at $40 \%$, exposure window $450 \mathrm{~ms}$, if heart rate was $>65 \mathrm{bpm}$. The fifth centre used a GE Healthcare Revolution scanner (Gantry rotation time $0.28 \mathrm{~s}, 2.5 \mathrm{~mm}$ collimation, Smart coverage acquisition $256 \times 0.625,224 \times 0.625$ or $192 \times 0.625 \mathrm{~mm}, 120 \mathrm{kV}$ tube voltage, $15 \mathrm{mAs}$ tube current) (GE, Chicago, IL, USA). Imaging was prospectively ECG-triggered at $75 \%$ of the R-R interval if heart rate was $<75 \mathrm{bpm}$ or at $350 \mathrm{~ms}$ after the QRS-complex if heart rate were $>75 \mathrm{bpm}$. 


\subsection{LA Size Measurement}

Seven trained radiographers, blinded to all clinical data, measured LA size on a SyngoVia (Siemens Healthcare Solutions, Erlangen, Germany) workstation. LA area was manually traced in axial slices at the level of the mitral annulus excluding the pulmonary veins, and the largest traced cross-section area was chosen (Figure 1). LA area was indexed for BSA, thereby calculating LA area index (LAindex = LAarea/BSA). To assess inter- and intra-observer variability, LA area measurements were repeated in 20 participants by each of the seven radiographers and in 140 participants by a second reader (M.H.F).
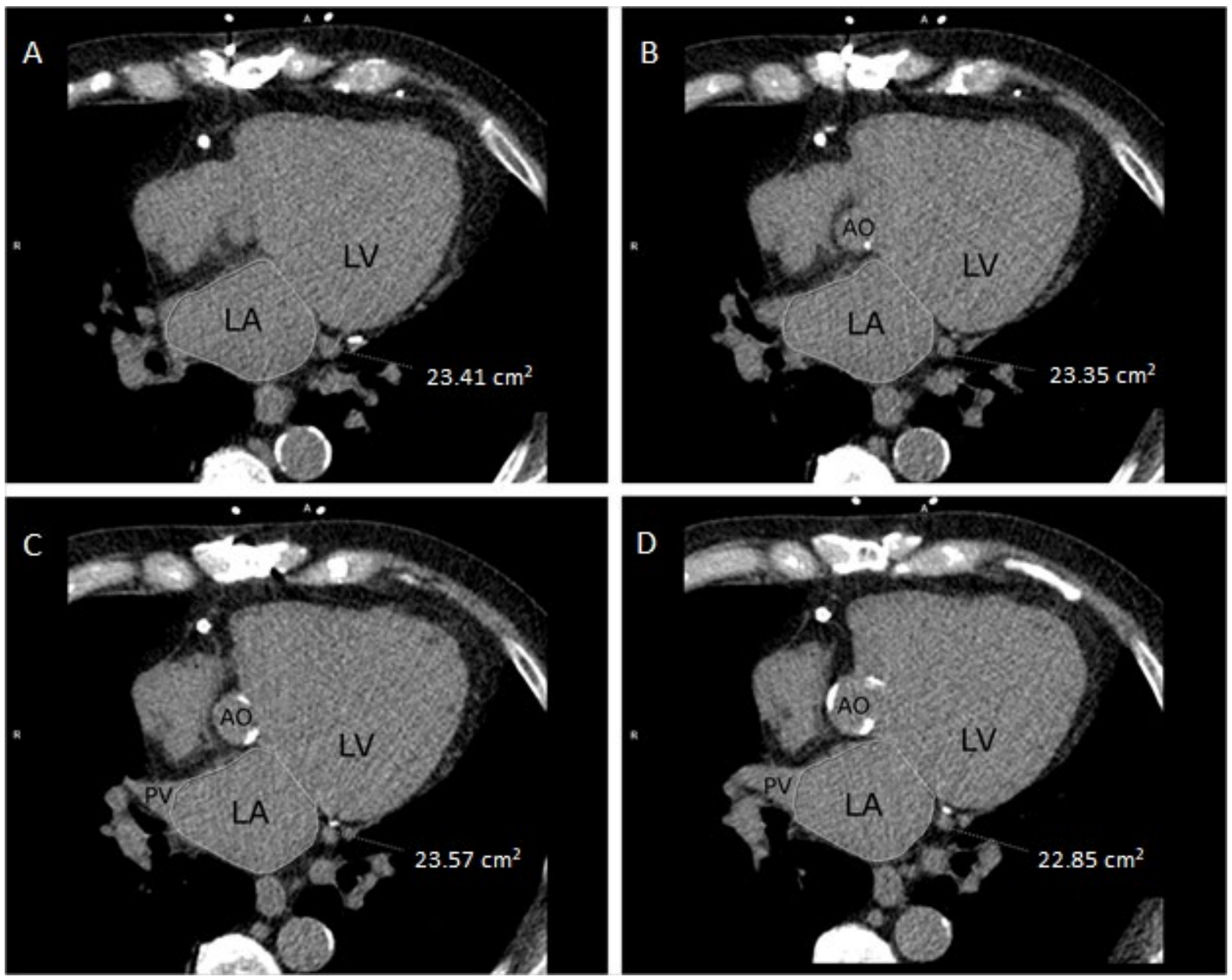

Figure 1. LA manually traced in multiple NCCT axial slices (A-D) to find the largest cross-section area $\left(\mathrm{cm}^{2}\right)$. $\mathrm{AO}$, aorta/aortic valve; $\mathrm{LA}$, left atrium; $\mathrm{LV}$, left ventricle; $\mathrm{PV}$, pulmonary vein.

\subsection{Risk Factors}

BSA was calculated using Du Bois formula [10]. Known hypertension was defined as use of antihypertensive medication, or a systolic blood pressure $>160 \mathrm{mmHg}$ or diastolic blood pressure $>100 \mathrm{mmHg}$, measured during the ankle-brachial index measurement, as described in DANCAVAS [9,11]. Diabetes was defined as current antidiabetic treatment, self-reported diabetes, or $\mathrm{HbA} 1 \mathrm{c}>48 \mathrm{mmol} / \mathrm{mol}$. Standardized methods were used to determine high- and low-density lipoprotein (HDL and LDL) and total cholesterol. Seven radiographers measured CAC score and valve calcification using the Agatston method [12]

\subsection{Echocardiography}

A supplementary echocardiography was performed in a subset of participants [13] according to recommendations from the European Echocardiographic Society [14]. All images were stored, and offline analyses were subsequently performed blinded for clinical 
data. The measurements included in this publication are left ventricle ejection fraction (EF) using Simpson's biplane method, and left ventricle mass derived from linear 2D.

\subsection{Statistical Analysis}

In all analyses, LA area was indexed to BSA. Continuous variables are presented as mean \pm standard deviation or $95 \%$ confidence interval $(\mathrm{CI})$ and categorical data as numeric (percentage). Non-normally distributed continuous variables are shown as median and interquartile range. Assumptions of normal distributions in data were assessed visually using quantile-quantile plots and numerically by means of the skewness and kurtosis tests for normality proposed by D'Agostino, Belanger, and D'Agostino [15,16]. Scatterplots of indexed LA area and explanatory variables were used to investigate functional relationships possibly suggesting normalising transformations for some variables. Univariate and multivariable linear regression using robust variance estimation were performed to assess the association between cardiovascular risk factors and LA area index. All variables were included in the multivariable model except for collinear variables such as diastolic and systolic blood pressure; here, the most clinically significant variable was chosen. To assess inter- and intra-observational differences Bland-Altman limits of agreement were performed with exact $95 \% \mathrm{CI}$ for the limits of agreement $[17,18]$ and supplemented by intraclass and Pearson's correlation coefficients. A $p$-value of $<0.05$ was considered significant for all other analyses. STATA version 16.0 (StataCorp LP, College Station, TX, USA) was used for statistical analysis.

\section{Results}

A total of 14,987 individuals participated in the screening trials. Of these, 3469 met the exclusion criteria, leaving 10,902 men and 616 women in this study (Figure 2).

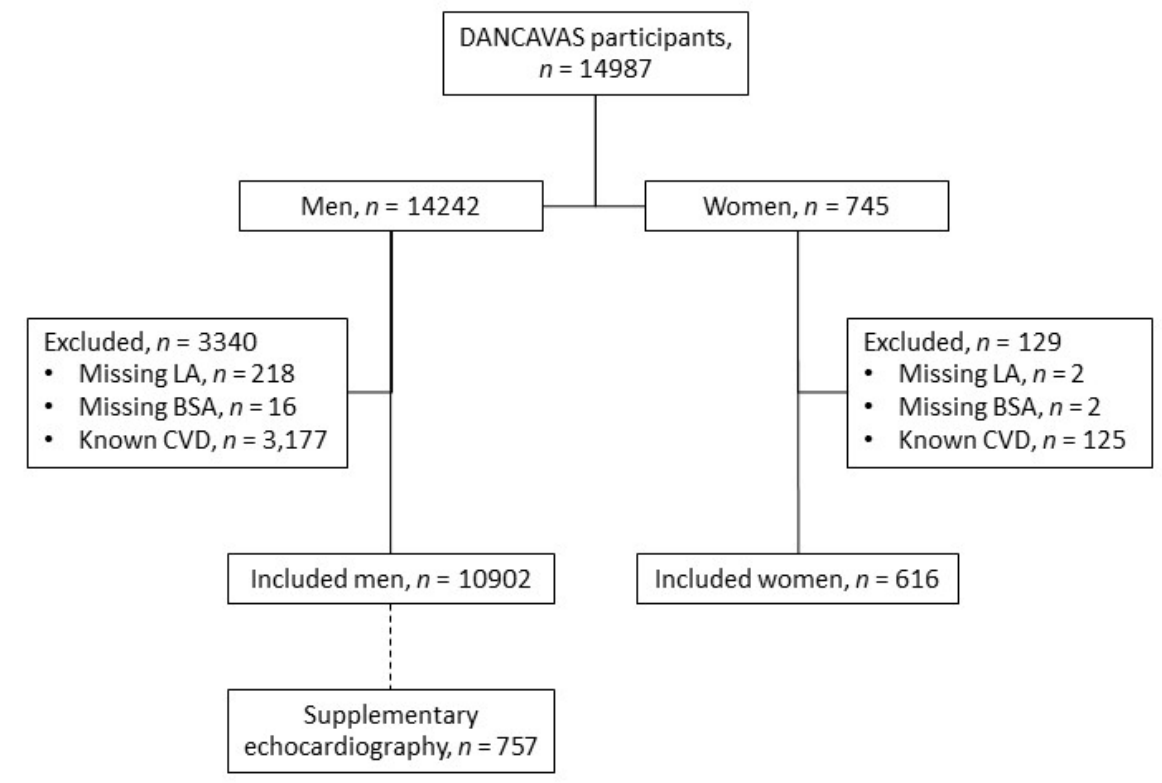

Figure 2. In- and exclusion criteria. BSA, body surface area; CVD, cardiovascular disease; LA, left atrium.

Mean age was 67 versus 68 years for men and women, respectively (Table 1). LA size was larger in men $\left(22.7 \mathrm{~cm}^{2} ; 95 \%\right.$ CI $\left.22.6-22.8\right)$ compared to women $\left(19.4 \mathrm{~cm}^{2} ; 95 \%\right.$ CI 19.1-19.7), but there was no difference between men $\left(11.1 \mathrm{~cm}^{2} / \mathrm{m}^{2}\right.$ (95\% CI 11.0-11.1) and women $\left(10.9 \mathrm{~cm}^{2} / \mathrm{m}^{2}\right.$ (95\% CI 10.7-11.1) when adjusting LA size for BSA. Risk factors differed among sexes: more men had diabetes, were current or former smokers, and had higher BMI, while more women had hypertension and dyslipidaemia. 
Table 1. Participant characteristic.

\begin{tabular}{|c|c|c|c|}
\hline Variable & Men & Women & $p$-Value \\
\hline$n$ & 10,902 & 616 & \\
\hline Age (years) & $67 \pm 4$ & $68 \pm 3$ & $<0.001$ \\
\hline LA size $\left(\mathrm{cm}^{2}\right)$ & $22.7 \pm 5.1$ & $19.4 \pm 4.4$ & $<0.001$ \\
\hline LA index $\left(\mathrm{cm}^{2} / \mathrm{m}^{2}\right)$ & $11.1 \pm 2.3$ & $10.9 \pm 2.3$ & 0.19 \\
\hline $\operatorname{BMI}\left(\mathrm{kg} / \mathrm{m}^{2}\right)$ & $27.9 \pm 4.2$ & $26.5 \pm 5.0$ & $<0.001$ \\
\hline BSA $\left(\mathrm{m}^{2}\right)$ & $2.0 \pm 0.2$ & $1.8 \pm 0.2$ & $<0.001$ \\
\hline \multicolumn{4}{|l|}{ Smoker } \\
\hline Active & $1733(16 \%)$ & $76(12 \%)$ & \\
\hline Former & $5376(50 \%)$ & $205(33 \%)$ & $<0.001$ \\
\hline Never & $3747(35 \%)$ & $334(54 \%)$ & \\
\hline Systolic blood pressure (mmHg) & $150 \pm 19$ & $155 \pm 20$ & $<0.001$ \\
\hline Diastolic blood pressure (mmHg) & $83 \pm 10$ & $83 \pm 9$ & 0.38 \\
\hline Pulse pressure $(\mathrm{mmHg})$ & $67 \pm 14$ & $72 \pm 16$ & $<0.001$ \\
\hline Hypertensive medication & $4172(38 \%)$ & $253(41 \%)$ & 0.16 \\
\hline Thiazide & $1166(11 \%)$ & $122(20 \%)$ & $<0.001$ \\
\hline Beta-blocker & $756(7 \%)$ & $68(11 \%)$ & $<0.001$ \\
\hline ACE inhibitor / ARB & $3134(29 \%)$ & $166(27 \%)$ & 0.34 \\
\hline Calcium antagonist & $1821(17 \%)$ & $83(14 \%)$ & 0.04 \\
\hline Hypertension & $6074(56 \%)$ & $385(63 \%)$ & 0.001 \\
\hline $\mathrm{HbA} 1 \mathrm{c}(\mathrm{mmol} / \mathrm{mol})$ & $39 \pm 7$ & $39 \pm 4$ & 0.81 \\
\hline Diabetes mellitus & $1166(11 \%)$ & $42(7 \%)$ & 0.002 \\
\hline Total cholesterol (mmol/L) & $5.2 \pm 1.0$ & $5.8 \pm 1.0$ & $<0.001$ \\
\hline $\operatorname{LDL}(\mathrm{mmol} / \mathrm{L})$ & $3.1 \pm 0.9$ & $3.2 \pm 0.9$ & $<0.001$ \\
\hline HDL $(\mathrm{mmol} / \mathrm{L})$ & $1.4 \pm 0.4$ & $1.7 \pm 0.5$ & $<0.001$ \\
\hline Lipid lowering medication & $2539(23 \%)$ & $190(31 \%)$ & $<0.001$ \\
\hline Dyslipidaemia & $8551(78 \%)$ & $555(90 \%)$ & $<0.001$ \\
\hline $\operatorname{eGFR}\left(\mathrm{mL} / \mathrm{min} / 1.73 \mathrm{~m}^{2}\right)$ & $79 \pm 13$ & $75 \pm 13$ & $<0.001$ \\
\hline CAC score $(\mathrm{AU})$ & $85(6-358)$ & $9(0-93)$ & $<0.001$ \\
\hline AVC score $(\mathrm{AU})$ & $3(0-65)$ & $0(0-22)$ & $<0.001$ \\
\hline Ascending aortic diameter (mm) & $37 \pm 4$ & $34 \pm 4$ & $<0.001$ \\
\hline
\end{tabular}

Data are expressed as mean $\pm \mathrm{SD}$ or number (\%). ACE, angiotensin converting enzyme; ARB, angiotensin II receptor blocker; AU, arbitrary unit; AVC, aortic valve calcification; BMI, body-mass index; BSA, body surface area CAC, coronary artery calcium score; eGFR, estimated glomerular filtration rate; HDL, high density lipoprotein; LDL, low density lipoprotein; LA, left atrium.

In the main analysis only including men, increasing age was associated with increasing LA size. In the multivariable analysis, LA size increased $0.06 \mathrm{~cm}^{2} / \mathrm{m}^{2}(95 \%$ CI $0.05-0.07$, $p<0.001$ ) per one-year increase in age, Table 2.

There was a negative association between smoking and LA size in the multivariable analysis. Former smokers had a decreased LA size of $0.42 \mathrm{~cm}^{2} / \mathrm{m}^{2}$, while LA size decreased by $1.10 \mathrm{~cm}^{2} / \mathrm{m}^{2}$ in current smokers, Table 2 .

Hypertension including systolic blood pressure, diastolic blood pressure, pulse pressure and anti-hypertensive treatment were significantly associated with an increased indexed LA size in univariate analysis. In the multivariable analysis, pulse pressure was chosen as the clinically most relevant variable, and the association between pulse pressure and increased LA size remained significant $\left(0.03 \mathrm{~cm}^{2} / \mathrm{m}^{2}\right.$ per $\left.\mathrm{mmHg}\right)$, Table 2. Exclusion of participants in anti-hypertensive treatment did not cause any changes $\left(0.03 \mathrm{~cm}^{2} / \mathrm{m}^{2}\right.$ per $\left.\mathrm{mmHg}\right)$, Table 3.

$\mathrm{HbA1c}$ and diabetes were associated with decreased LA size, and this association persisted in the multivariable analysis as $\mathrm{HbA1c}$ was associated with a decreased LA size $\left(0.02 \mathrm{~cm}^{2} / \mathrm{m}^{2}\right.$ per $\left.\mathrm{mmol} / \mathrm{mol}\right)$. In participants without diabetes, $\mathrm{HbA} 1 \mathrm{c}$ remained associated with decreased LA size $\left(0.01 \mathrm{~cm}^{2} / \mathrm{m}^{2}\right.$ per $\left.\mathrm{mmol} / \mathrm{mol}\right)$. 
Table 2. Linear regression of left atrium area index $\left(\mathrm{cm}^{2} / \mathrm{m}^{2}\right)$ in men $(n=10,902)$.

\begin{tabular}{|c|c|c|c|c|c|}
\hline \multirow[b]{2}{*}{ Variable } & \multicolumn{3}{|c|}{ Univariate } & \multicolumn{2}{|c|}{ Multivariable (R-Squared $=0.068)$} \\
\hline & $\Delta$ LA Area Index $(95 \% \mathrm{CI})$ & $p$-Value & R-Squared & $\Delta$ LA Area Index $(95 \% \mathrm{CI})$ & $p$-Value \\
\hline Age (years) * & $0.08(0.07 ; 0.09)$ & $<0.001$ & 0.016 & $0.06(0.05 ; 0.07)$ & $<0.001$ \\
\hline \multicolumn{6}{|l|}{ Smoking } \\
\hline Former & $-0.40(-0.50 ;-0.31)$ & $<0.001$ & & $-0.42(-0.51 ;-0.32)$ & $<0.001$ \\
\hline Current & $-1.13(-1.26 ;-1.00)$ & $<0.001$ & 0.026 & $-1.07(-1.20 ;-0.94)$ & $<0.001$ \\
\hline Systolic blood pressure $(\mathrm{mmHg}) *$ & $0.021(0.019 ; 0.024)$ & $<0.001$ & 0.030 & - & - \\
\hline Diastolic blood pressure (mmHg) * & $0.017(0.012 ; 0.021)$ & $<0.001$ & 0.005 & - & - \\
\hline Pulse pressure $(\mathrm{mmHg}) *$ & $0.029(0.026 ; 0.032)$ & $<0.001$ & 0.031 & $0.026(0.023 ; 0.029)$ & $<0.001$ \\
\hline Hypertensive medication & $0.36(0.27 ; 0.45)$ & $<0.001$ & 0.006 & - & - \\
\hline Hypertension & $0.60(0.52 ; 0.69)$ & $<0.001$ & 0.017 & - & - \\
\hline $\mathrm{HbA} 1 \mathrm{c}(\mathrm{mmol} / \mathrm{mol}) *$ & $-0.012(-0.018 ;-0.006)$ & $<0.001$ & 0.0014 & $-0.016(-0.022 ;-0.010)$ & $<0.001$ \\
\hline Diabetes mellitus & $-0.16(-0.30 ;-0.02)$ & 0.02 & 0.0005 & - & - \\
\hline Total cholesterol $(\mathrm{mmol} / \mathrm{L})$ * & $-0.08(-0.13 ;-0.04)$ & $<0.001$ & 0.0014 & $-0.11(-0.15 ;-0.07)$ & $<0.001$ \\
\hline $\operatorname{LDL}(\mathrm{mmol} / \mathrm{L}) *$ & $-0.08(-0.12 ;-0.03)$ & 0.001 & 0.0010 & - & - \\
\hline $\mathrm{HDL}(\mathrm{mmol} / \mathrm{L}) *$ & $0.14(0.04 ; 0.24)$ & 0.008 & 0.0006 & - & - \\
\hline Lipid lowering medication & $0.004(-0.010 ; 0.108)$ & 0.93 & 0.0000 & - & - \\
\hline Dyslipidaemia & $-0.14(-0.24 ;-0.03)$ & 0.01 & 0.0006 & - & - \\
\hline $\operatorname{eGFR}\left(\mathrm{mL} / \mathrm{min} / 1.73 \mathrm{~m}^{2}\right)$ * & $-0.001(-0.004 ; 0.002)$ & 0.52 & 0.0000 & - & - \\
\hline CAC score $(\mathrm{AU}) *$ & $0.0002(0.0002 ; 0.0003)$ & $<0.001$ & 0.0047 & - & - \\
\hline AVC score $(\mathrm{AU}) *$ & $0.0005(0.0004 ; 0.0007)$ & $<0.001$ & 0.0046 & - & - \\
\hline Ascending aortic diameter $(\mathrm{mm}) *$ & $0.11(0.10 ; 0.13)$ & $<0.001$ & 0.0039 & - & - \\
\hline
\end{tabular}

* By 1 unit increment. AU, arbitrary unit; AVC, aortic valve calcification; CAC, coronary artery calcium score; eGFR, estimated glomerular filtration rate; HDL, high density lipoprotein; LDL, low density lipoprotein.

Table 3. Linear regression of LA area index $\left(\mathrm{cm}^{2} / \mathrm{m}^{2}\right)$ in men-a subgroup analysis.

\begin{tabular}{|c|c|c|c|c|c|c|}
\hline \multirow[b]{2}{*}{ Variable } & \multicolumn{2}{|c|}{ Univariate } & \multicolumn{4}{|c|}{ Multivariable \# } \\
\hline & $\begin{array}{c}\Delta \text { LA Area Index } \\
(95 \% \mathrm{CI})\end{array}$ & $p$-Value & R-Squared & $\begin{array}{c}\Delta \text { LA area index } \\
(95 \% \mathrm{CI})\end{array}$ & $p$-Value & R-Squared \\
\hline \multicolumn{7}{|c|}{ No anti-hypertensive treatment $(n=6693)$} \\
\hline Pulse blood pressure $(\mathrm{mmHg}) *$ & $0.031(0.027 ; 0.035)$ & $<0.0001$ & 0.036 & $0.028(0.024 ; 0.032)$ & $<0.001$ & 0.070 \\
\hline \multicolumn{7}{|c|}{ No anti-diabetic treatment $(n=9976)$} \\
\hline $\mathrm{HbA} 1 \mathrm{c}(\mathrm{mmol} / \mathrm{mol}) *$ & $-0.009(-0.018 ;-0.001)$ & 0.04 & 0.0004 & $-0.010(-0.018 ;-0.001)$ & 0.03 & 0.067 \\
\hline \multicolumn{7}{|c|}{ No lipid-lowering treatment $(n=8319)$} \\
\hline Total cholesterol $(\mathrm{mmol} / \mathrm{L}) *$ & $-0.11(-0.17 ;-0.06)$ & $<0.0001$ & 0.0020 & $-0.13(-0.19 ;-0.08)$ & $<0.001$ & 0.072 \\
\hline
\end{tabular}

* By 1 unit increment. "\# Adjusted for age, smoking, pulse blood pressure, HbA1c, total cholesterol.

Total cholesterol and LDL were associated with decreased LA size, while HDL was associated with increased LA size. In the multivariable analysis, a decrease of $0.11 \mathrm{~cm}^{2} / \mathrm{m}^{2}$ in LA size per mmol/L increase in total cholesterol was observed. These findings persisted in a subgroup analysis of participants without lipid-lowering treatment $\left(0.13 \mathrm{~cm}^{2} / \mathrm{m}^{2}\right.$ per $\left.\mathrm{mmol} / \mathrm{L}\right)$. As the CT scan acquisition depended on the patient heart rate, some scans were performed in the systole (patients with high heart rates) and some in the diastole (patients with low heart rates). As atrial volume is maximal in systole and minimal in diastole, this causes a possible bias. Supplementary Table S1 shows the respective analyses stratified by heart rate. We found no substantial differences in subgroups of participants with heart rates below 65 vs. heart rates 65 to 75 vs. heart rates above 75 .

An echocardiography was available in 757 of the 10,902 men. After inclusion of left ventricle EF and mass, age and pulse pressure remained positively associated with LA size, while smoking, $\mathrm{HbA} 1 \mathrm{c}$ and total cholesterol remained negatively associated with LA size, Table 4 . In this supplementary model, increasing left ventricle EF was associated with decreased LA size, while increasing left ventricle mass was associated with increased LA size. If the echocardiographic measurement of left atrial volume was used instead of the CT-based measurement, current smoking kept associated with decreased left atrial 
volume, and left ventricular mass was associated with increased left atrial volume, Table 4. The remaining variables lost significance, but all retained the direction (non-significantly associated with a decreased or increased left atrial volume). The diastolic measurement E/e was not associated with LA size, and was accordingly excluded from the model. Additionally, CAC score, AVC score, and ascending aortic diameter were all associated with increased indexed LA size, Table 2. As neither CAC nor AVC score are risk factors to LA size, they were not included in the multivariable model.

In the univariate analysis including women, age was positively associated with LA size $\left(0.07 \mathrm{~cm}^{2} / \mathrm{m}^{2}(95 \%\right.$ CI 0.01-0.12, $\left.p=0.01)\right)$, but lost significance in the multivariable analysis, Table 5. Pulse pressure was associated with increasing LA size $\left(0.03 \mathrm{~cm}^{2} / \mathrm{m}^{2}\right.$ per $\left.\mathrm{mmHg}\right)$ in the multivariable analysis, while total cholesterol was associated with decreasing LA size $\left(0.22 \mathrm{~cm}^{2} / \mathrm{m}^{2}\right.$ per $\left.\mathrm{mmol} / \mathrm{L}\right)$. In current smokers, LA size decreased, with $0.77 \mathrm{~cm}^{2} / \mathrm{m}^{2}$ $(95 \%$ CI $-1.33 ;-0.21, p=0.007)$ in the univariate analysis, but lost significance in the multivariable analysis. Former smoking and $\mathrm{HbA1c}$ was not associated with LA size in the univariate or multivariable analysis.

Table 4. Linear multivariable regression of left atrium area $\left(\mathrm{cm}^{2} / \mathrm{m}^{2}\right)$ by cardiac CT $(n=757)$ or volume $\left(\mathrm{mL} / \mathrm{m}^{2}\right)$ derived by echocardiographic $(n=709)$-a subgroup analysis including echocardiographic measurements.

\begin{tabular}{|c|c|c|c|c|}
\hline \multirow[b]{2}{*}{ Variable } & \multicolumn{2}{|c|}{$\begin{array}{c}\text { Atrial Area }\left(\mathrm{cm}^{2} / \mathrm{m}^{2}\right) \\
\text { Derived by Cardiac CT }\end{array}$} & \multicolumn{2}{|c|}{$\begin{array}{c}\text { Atrial Volume }\left(\mathrm{mL} / \mathrm{m}^{2}\right) \\
\text { Derived by Echocardiographic }\end{array}$} \\
\hline & $\Delta$ LA Area Index $(95 \% \mathrm{CI})$ & $p$-Value & $\Delta$ LA Area Index $(95 \% \mathrm{CI})$ & $p$-Value \\
\hline Age (years) * & $0.08(0.02 ; 0.14)$ & 0.01 & $0.05(-0.15 ; 0.25)$ & 0.61 \\
\hline \multicolumn{5}{|l|}{ Smoking } \\
\hline Former & $-0.93(-1.31 ;-0.55)$ & $<0.001$ & $-0.98(-2.19 ; 0.24)$ & 0.12 \\
\hline Current & $-1.30(-1.80 ;-0.80)$ & $<0.001$ & $-2.50(-4.10 ;-0.91)$ & 0.002 \\
\hline Pulse pressure $(\mathrm{mmHg}) *$ & $0.02(0.01 ;-0.03)$ & $<0.01$ & $0.03(-0.01 ; 0.07)$ & 0.10 \\
\hline $\mathrm{HbA} 1 \mathrm{c}(\mathrm{mmol} / \mathrm{mol}) *$ & $-0.03(-0.05 ;-0.01)$ & $<0.01$ & $-0.06(-0.13 ; 0.00)$ & 0.06 \\
\hline Total cholesterol $(\mathrm{mmol} / \mathrm{L}) *$ & $-0.17(-0.32 ;-0.01)$ & 0.04 & $-0.27(-0.77 ; 0.22)$ & 0.28 \\
\hline Left ventricle ejection fraction $(\%) *$ & $-0.03(-0.06 ;-0.00)$ & 0.04 & $-0.08(-0.17 ; 0.00)$ & 0.054 \\
\hline Left ventricle mass $(\mathrm{g}) *$ & $0.01(0.01 ; 0.01)$ & $<0.001$ & $0.04(0.03 ; 0.05)$ & $<0.001$ \\
\hline
\end{tabular}

${ }^{*}$ By 1 unit increment.

Table 5. Linear regression of left atrium area index $\left(\mathrm{cm}^{2} / \mathrm{m}^{2}\right)$ in women $(n=606)$.

\begin{tabular}{|c|c|c|c|c|c|}
\hline \multirow[b]{2}{*}{ Variable } & \multicolumn{3}{|c|}{ Univariate } & \multicolumn{2}{|c|}{ Multivariable $(\mathrm{R}-$ Squared $=0.082)$} \\
\hline & $\Delta$ LA Area Index $(95 \% \mathrm{CI})$ & $p$-Value & R-Squared & $\Delta$ LA Area Index $(95 \% \mathrm{CI})$ & $p$-Value \\
\hline Age (years) * & $0.07(0.01 ; 0.12)$ & 0.01 & 0.0097 & $0.02(-0.03 ; 0.08)$ & 0.42 \\
\hline \multicolumn{6}{|l|}{ Smoking } \\
\hline Former & $-0.09(-0.48 ; 0.30)$ & 0.64 & & $-0.10(-0.49 ; 0.29)$ & 0.62 \\
\hline Current & $-0.77(-1.33 ;-0.21)$ & 0.007 & 0.0117 & $-0.54(-1.10 ; 0.03)$ & 0.06 \\
\hline Pulse pressure $(\mathrm{mmHg}) *$ & $0.04(0.02 ; 0.05)$ & $<0.0001$ & 0.0641 & $0.03(0.02 ;-0.05)$ & $<0.001$ \\
\hline $\mathrm{HbA} 1 \mathrm{c}(\mathrm{mmol} / \mathrm{mol})^{*}$ & $0.03(-0.01 ; 0.07)$ & 0.11 & 0.0044 & $0.01(-0.03 ; 0.05)$ & 0.57 \\
\hline Total cholesterol $(\mathrm{mmol} / \mathrm{L}) *$ & $-0.20(-0.77 ;-0.03)$ & 0.02 & 0.0083 & $-0.22(-0.40 ;-0.05)$ & 0.01 \\
\hline
\end{tabular}

* By 1 unit increment.

Inter- and intra-observer agreement of LA measurements were performed in 140 participants with a Pearson's correlation of $r=0.98$ and $r=0.97(p<0.0001)$. Agreement by Bland-Altman plots are shown in Figure 3 with a mean difference in LA area of $-0.02 \mathrm{~cm}^{2}$ and $0.58 \mathrm{~cm}^{2}$, the limits of agreement were -2.36 to 2.33 and -2.44 to 3.55 , and outer $95 \%$ confidence limits of these were -2.68 and 2.65 , as well as -3.03 and 4.19 in inter- and intra-observer analyses, respectively. Intraclass correlation coefficients (with respective $95 \%$ confidence intervals) were $0.98(0.97-0.99)$ for the inter- and $0.96(0.95-0.97)$ for the intra-observer comparison. 

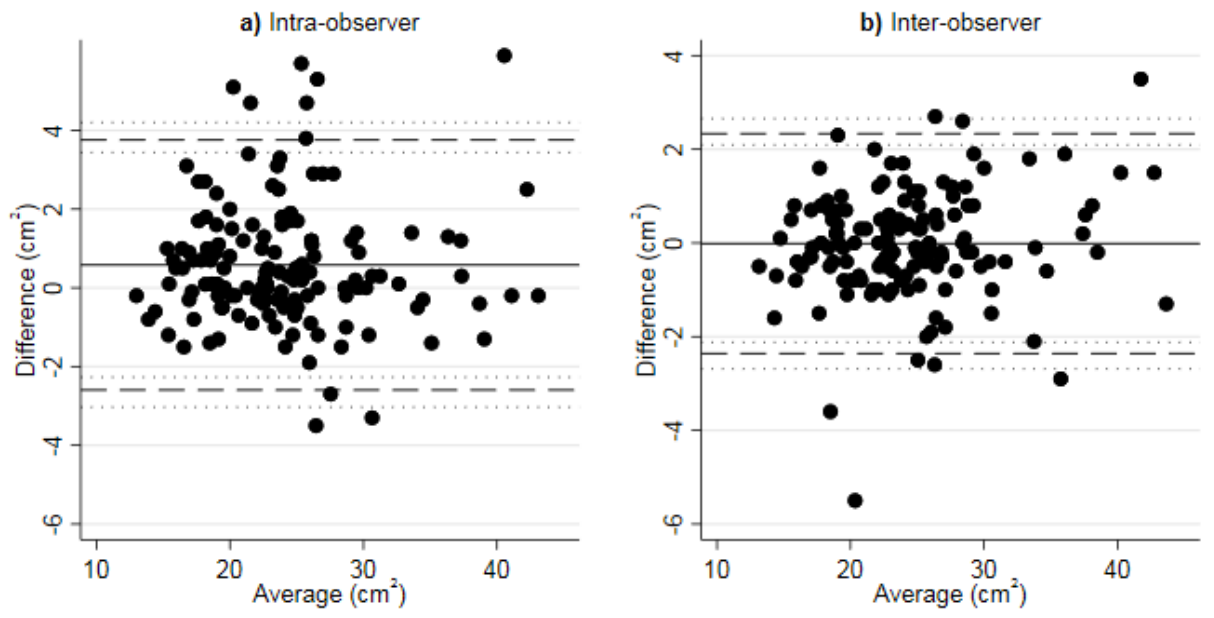

Figure 3. Bland-Altman plots comparing (a) intra-observer and (b) inter-observer agreement of LA area $\left(\mathrm{cm}^{2}\right)$ measurements in NCCT $(n=140)$. Solid line: average difference (bias estimate). Dashed lines: 95\% Bland-Altman limits of agreement. Dotted lines: exact 95\% CI for Bland-Altman limits of agreement.

\section{Discussion}

We examined the association between indexed LA area measured by NCCT and classical cardiovascular risk factors in participants without any overt cardiovascular disease. Age and hypertension were associated with LA size, but surprisingly we experienced that not only smoking, but also diabetes and dyslipidaemia were associated with decreased LA size.

Our data demonstrate that a yearly increase in age is associated with an increased LA area. As both atrial size and risk of AF increase by age, remodelling and atrial dysfunction are seen as a direct consequence of natural aging; however, studies using echocardiographic data found no increase in maximal LA volume with normal aging [19]. Atrial enlargement may therefore be due to accumulated risk factors and ventricular pathology seen with increasing age rather than caused by the aging process itself. When adjusting our analysis for all other cardiovascular risk factors, a somewhat smaller effect on atrial area was seen; however, age remained independently associated with LA size. As expected, hypertension, pulse pressure and systolic and diastolic blood pressure were associated with an increased LA area, and the LA area remained significantly increased when the analysis was adjusted for other cardiovascular risk factors. The left ventricle and conditions herein have a direct effect on the LA. As hypertension affects both ventricular filling pressure and ventricular diastolic dysfunction, this will inevitably lead to an increased atrial pressure causing increased wall tension and hence facilitate remodelling. Furthermore, an independent association of LA volume with diastolic dysfunction has been demonstrated [20]. Adjusting our analysis for left ventricle EF and mass did not alter the findings concerning the association between pulse pressure and LA area.

Among classic risk factors, smoking is a key contributor to cardiovascular disease. Several studies have found smoking to be associated with incident AF, and meta-analyses of prospective studies showed a dose-dependent association [21,22]. Tobacco use has several adverse effects and leads to conditions such as diabetes [23] and hypertension [24-26], which are known risk factors for AF. Nicotine has been associated with atrial fibrosis, which impairs intracellular conduction leading to arrhythmias [27]. Nicotine has also been shown to be a potent blocker of ion channels in the atrial myocytes [28]. In our study, a negative correlation between both current and former smoking and LA area was seen. As smoking is associated with $\mathrm{AF}$ and an indisputable relationship exists between LA size and AF, our findings seem paradoxical. The pathophysiological mechanisms behind these findings are not fully clarified. We examined individuals without know cardiovascular disease, leaving 
out participants with known AF. One could therefore speculate that our results illustrates the pathophysiological changes of smoking preceding disease manifestation and atrial enlargement occurs later in the development of AF. However, this cannot fully explain our findings. As others have described a correlation of decreased LA size with smoking [29], our results are not likely to be coincidental. Hyper-inflated lungs, as seen in smokers with emphysema, could have decreased intrathoracic blood volume and could thereby decrease preload, leading to decreased filling and dimensions of the chambers in the heart [30,31].

A similar paradoxical correlation was found for diabetes and dyslipidaemia. The negative association between $\mathrm{HbA} 1 \mathrm{c}$ level and LA size in men, conflicts with current literature $[32,33]$. These two papers $[32,33]$ are case-control studies including 40 and 60 patients with diabetes, respectively, and they are based on echocardiographic measurements, thus with a risk confirmation bias. The effect of diabetes on atrial size could be reduced when indexing LA size to body size, which is a major contributor to diabetes. A prior CT study including 3945 individuals, hereof 272 with diabetes, used LA size indexed to body size and found no association to diabetes in men, but an association to diabetes in women [29]. In our study, including 1166 men and 42 women with diabetes, we found a negative association between LA size and $\mathrm{HbA} 1 \mathrm{c}$ among men, but not among women. In conclusion, the association between atrial size and diabetes may not be finally clarified. One other study has also reported a decreased LA size with increasing cholesterol level [29].

We found no rational physiological explanation for these surprising findings, but the results may be explained by inclusion of individuals from the general population in the DANCAVAS trial and our exclusion of individuals with known cardiovascular disease. Thus, we are studying healthy individuals without known cardiovascular disease, and it may be speculated that smoking, increased $\mathrm{HbA} 1 \mathrm{c}$ and total cholesterol in the very beginning will induce fibrosis and shrinking of the LA. Over time, this will lead to contractile dysfunction and ultimate lead to dilatation and arrhythmias and cardiovascular disease. Thus, our findings could be partly explained by our exclusion criteria. However, the cross-sectional design does not permit causal inference.

The strength of our study is the large size of the study population comprising of randomly selected individuals with a high attendance rate; therefore, the risk of selections bias is low. Importantly, we excluded individuals with known cardiovascular disease, and our population consists primarily of Caucasian men aged 60-75 years; hence, the generalisation for females, other ethnic groups and different age groups can be questioned. An apparent limitation is the use of an area assessment rather than a full volume assessment of the LA. However, earlier studies have compared this axial measurement with 3D CT and MRI measurements of the left atrium and shown a high correlation [34,35]. Furthermore, CT measurements present high reproducibility as shown in our inter- and intra-observer agreement analysis whereas echocardiographic measurements are more difficult to reproduce [36]. This is also reflected by our analyses, as analyses based on the echocardiographic measurements were not as manifest as analyses based on CT measurements. LA size was measured at different stages of the heart cycle entailing a risk of underestimating LA size, if the scan was performed in the diastole. However, we found no substantial differences in subgroups of participants with a systolic versus a diastolic scan (Supplementary Table S1). Low R-squared values were seen in our results, which is expected in a model of healthy individuals where diseases known to influence LA size such as atrial fibrillation have been deliberately excluded. The participants were submitted to a somewhat stressful screening setting and to avoid over-diagnosing hypertension, the definition for hypertension was $160 / 100$. This is not in accordance with the guidelines, but in our adjusted model, we did include pulse pressure instead of systolic or diastolic blood pressure. Excessive confounder adjustment was performed for all known risk factors, but the risk of residual confounding will always exist in such an observational study. 


\section{Conclusions}

The associations between classic cardiovascular risk factor and LA size seen in this study may seem puzzling; however, they indicate that the pathophysiology behind atrial cardiomyopathy, remodelling, disease progression and consequently manifest cardiovascular disease may be even more complex than first assumed.

Supplementary Materials: The following supporting information can be downloaded at: https:// www.mdpi.com/article/10.3390/diagnostics12020244/s1, Table S1: Linear regression of left atrium area index $\left(\mathrm{cm}^{2} / \mathrm{m}^{2}\right)$ in men, analyzed in three subgroups depending on heart rate.

Author Contributions: Conceptualisation, J.S.L. and A.C.P.D.; methodology, M.H.F., J.S.L. and A.C.P.D.; software, M.H.F.; validation, M.H.F. and A.C.P.D.; formal analysis, M.H.F. and A.C.P.D.; investigation, M.H.F., J.S.L., A.B., F.H.S., L.F., J.L., M.K., M.B., G.U., K.E., L.K. and A.C.P.D.; resources, M.H.F., J.S.L., A.B., F.H.S., L.F., J.L., M.K., M.B., G.U., K.E., L.K. and A.C.P.D.; data curation, M.H.F.; writing—original draft preparation, M.H.F.; writing—review \& editing, M.H.F., O.G. and A.C.P.D.; visualisation, M.H.F.; supervision, J.S.L., O.G. and A.C.P.D.; project administration, M.H.F. and A.C.P.D.; funding acquisition, M.H.F., J.S.L. and A.C.P.D. All authors have read and agreed to the published version of the manuscript.

Funding: The University of Southern Denmark [no grant number] and the Region of Southern Denmark [journal number: 17/15121] supported by this work.

Institutional Review Board Statement: The study was conducted according to the guidelines of the Declaration of Helsinki. The Regional Scientific Ethical Committee of Southern Denmark and the Danish Data Protection Agency approved the study (S-20140028 and S-20160164).

Informed Consent Statement: Informed consent was obtained from all subjects involved in the study.

Data Availability Statement: Data are stored at the Open Patient data Explorative Network (OPEN), https:/ / open.rsyd.dk/redcap/, and is available upon request.

Conflicts of Interest: The authors declare no conflict of interest.

$\begin{array}{ll}\text { Abbreviations } \\ \text { AVC } & \text { aortic valve calcification } \\ \text { BMI } & \text { body mass index } \\ \text { BSA } & \text { body surface area } \\ \text { CAC } & \text { coronary artery calcium } \\ \text { HDL } & \text { high density lipoprotein } \\ \text { EF } & \text { ejection fraction } \\ \text { LA } & \text { left atrial } \\ \text { LDL } & \text { low density lipoprotein } \\ \text { NCCT } & \text { non-contrast computed tomography }\end{array}$

\section{References}

1. Tsang, T.S.; Barnes, M.E.; Bailey, K.R.; Leibson, C.L.; Montgomery, S.C.; Takemoto, Y.; Diamond, P.M.; Marra, M.A.; Gersh, B.J.; Wiebers, D.O.; et al. Left atrial volume: Important risk marker of incident atrial fibrillation in 1655 older men and women. Mayo Clin. Proc. 2001, 76, 467-475. [CrossRef] [PubMed]

2. Kizer, J.R.; Bella, J.N.; Palmieri, V.; Liu, J.E.; Best, L.G.; Lee, E.T.; Roman, M.J.; Devereux, R.B. Left atrial diameter as an independent predictor of first clinical cardiovascular events in middle-aged and elderly adults: The Strong Heart Study (SHS). Am. Heart J. 2006, 151, 412-418. [CrossRef] [PubMed]

3. Rossi, A.; Temporelli, P.L.; Quintana, M.; Dini, F.L.; Ghio, S.; Hillis, G.S.; Klein, A.L.; Marsan, N.A.; Prior, D.L.; Yu, C.M.; et al. Independent relationship of left atrial size and mortality in patients with heart failure: An individual patient meta-analysis of longitudinal data (MeRGE Heart Failure). Eur. J. Heart Fail. 2009, 11, 929-936. [CrossRef] [PubMed]

4. Fredgart, M.H.; Lindholt, J.S.; Brandes, A.; Steffensen, F.H.; Frost, L.; Lambrechtsen, J.; Karon, M.; Busk, M.; Urbonaviciene, G.; Egstrup, K.; et al. Prognostic importance of left atrial size measured by non-contrast cardiac computed tomography-A DANCAVAS study. Int. J. Cardiol. 2021, 328, 220-226. [CrossRef]

5. Miller, J.D.; Aronis, K.N.; Chrispin, J.; Patil, K.D.; Marine, J.E.; Martin, S.S.; Blaha, M.J.; Blumenthal, R.S.; Calkins, H. Obesity, Exercise, Obstructive Sleep Apnea, and Modifiable Atherosclerotic Cardiovascular Disease Risk Factors in Atrial Fibrillation. J. Am. Coll. Cardiol. 2015, 66, 2899-2906. [CrossRef] 
6. Erbel, R.; Möhlenkamp, S.; Moebus, S.; Schmermund, A.; Lehmann, N.; Stang, A.; Dragano, N.; Grönemeyer, D.; Seibel, R.; Kälsch, H.; et al. Coronary risk stratification, discrimination, and reclassification improvement based on quantification of subclinical coronary atherosclerosis: The Heinz Nixdorf Recall study. J. Am. Coll. Cardiol. 2010, 56, 1397-1406. [CrossRef]

7. Yeboah, J.; McClelland, R.L.; Polonsky, T.S.; Burke, G.L.; Sibley, C.T.; O’Leary, D.; Carr, J.J.; Goff, D.C.; Greenland, P.; Herrington, D.M. Comparison of novel risk markers for improvement in cardiovascular risk assessment in intermediate-risk individuals. JAMA 2012, 308, 788-795. [CrossRef]

8. Diederichsen, A.C.; Rasmussen, L.M.; Søgaard, R.; Lambrechtsen, J.; Steffensen, F.H.; Frost, L.; Egstrup, K.; Urbonaviciene, G.; Busk, M.; Olsen, M.H.; et al. The Danish Cardiovascular Screening Trial (DANCAVAS): Study protocol for a randomized controlled trial. Trials 2015, 16, 554. [CrossRef]

9. Kvist, T.V.; Lindholt, J.S.; Rasmussen, L.M.; Søgaard, R.; Lambrechtsen, J.; Steffensen, F.H.; Frost, L.; Olsen, M.H.; Mickley, H.; Hallas, J.; et al. The DanCavas Pilot Study of Multifaceted Screening for Subclinical Cardiovascular Disease in Men and Women Aged 65-74 Years. Eur. J. Vasc. Endovasc. Surg. 2017, 53, 123-131. [CrossRef]

10. Du Bois, D.; Du Bois, E.F. A formula to estimate the approximate surface area if height and weight be known, 1916. Nutrition 1989, 5, 303-311; discussion 312-313.

11. Lindholt, J.S.; Rasmussen, L.M.; Søgaard, R.; Lambrechtsen, J.; Steffensen, F.H.; Frost, L.; Egstrup, K.; Urbonaviciene, G.; Busk, M.; Olsen, M.H.; et al. Baseline findings of the population-based, randomized, multifaceted Danish cardiovascular screening trial (DANCAVAS) of men aged 65-74 years. Br. J. Surg. 2019, 106, 862-871. [CrossRef]

12. Agatston, A.S.; Janowitz, W.R.; Hildner, F.J.; Zusmer, N.R.; Viamonte, M., Jr.; Detrano, R. Quantification of coronary artery calcium using ultrafast computed tomography. J. Am. Coll. Cardiol. 1990, 15, 827-832. [CrossRef]

13. Khurrami, L.; Møller, J.E.; Lindholt, J.S.; Dahl, J.S.; Fredgart, M.H.; Obel, L.M.; Steffensen, F.H.; Urbonaviciene, G.; Lambrechtsen, J.; Diederichsen, A.C.P. Aortic valve calcification among elderly males from the general population, associated echocardiographic findings, and clinical implications. Eur. Heart J. Cardiovasc. Imaging 2021, in press. [CrossRef]

14. Lang, R.M.; Badano, L.P.; Mor-Avi, V.; Afilalo, J.; Armstrong, A.; Ernande, L.; Flachskampf, F.A.; Foster, E.; Goldstein, S.A.; Kuznetsova, T.; et al. Recommendations for cardiac chamber quantification by echocardiography in adults: An update from the American Society of Echocardiography and the European Association of Cardiovascular Imaging. Eur. Heart J. Cardiovasc. Imaging 2015, 16, 233-270. [CrossRef]

15. D'Agostino, R.B.; Belanger, A.J.; D'Agostino, R.B., Jr. A suggestion for using powerful and informative tests of normality. Am. Stat. 1990, 44, 316-321. [CrossRef]

16. Royston, P. sg3.5: Comment on sg3.4 and an improved D'Agostino test. Stata Tech. Bull. 1991, 3, 23-24. Available online: https://www.stata-press.com/journals/stbcontents/stb3.pdf (accessed on 3 January 2022).

17. Carkeet, A. Exact parametric confidence intervals for Bland-Altman limits of agreement. Optom. Vis. Sci. 2015, 92, e71-e80. [CrossRef]

18. Carkeet, A.; Goh, Y.T. Confidence and coverage for Bland-Altman limits of agreement and their approximate confidence intervals. Stat. Methods Med. Res. 2018, 27, 1559-1574. [CrossRef]

19. Thomas, L.; Levett, K.; Boyd, A.; Leung, D.Y.; Schiller, N.B.; Ross, D.L. Compensatory changes in atrial volumes with normal aging: Is atrial enlargement inevitable? J. Am. Coll. Cardiol. 2002, 40, 1630-1635. [CrossRef]

20. Tsang, T.S.; Barnes, M.E.; Gersh, B.J.; Bailey, K.R.; Seward, J.B. Left atrial volume as a morphophysiologic expression of left ventricular diastolic dysfunction and relation to cardiovascular risk burden. Am. J. Cardiol. 2002, 90, 1284-1289. [CrossRef]

21. Zhu, W.; Yuan, P.; Shen, Y.; Wan, R.; Hong, K. Association of smoking with the risk of incident atrial fibrillation: A meta-analysis of prospective studies. Int. J. Cardiol. 2016, 218, 259-266. [CrossRef]

22. Aune, D.; Schlesinger, S.; Norat, T.; Riboli, E. Tobacco smoking and the risk of atrial fibrillation: A systematic review and meta-analysis of prospective studies. Eur. J. Prev. Cardiol. 2018, 25, 1437-1451. [CrossRef]

23. Pan, A.; Wang, Y.; Talaei, M.; Hu, F.B.; Wu, T. Relation of active, passive, and quitting smoking with incident type 2 diabetes: A systematic review and meta-analysis. Lancet Diabetes Endocrinol. 2015, 3, 958-967. [CrossRef]

24. Halperin, R.O.; Gaziano, J.M.; Sesso, H.D. Smoking and the risk of incident hypertension in middle-aged and older men. Am. J. Hypertens. 2008, 21, 148-152. [CrossRef]

25. Dochi, M.; Sakata, K.; Oishi, M.; Tanaka, K.; Kobayashi, E.; Suwazono, Y. Smoking as an independent risk factor for hypertension: A 14-year longitudinal study in male Japanese workers. Tohoku J. Exp. Med. 2009, 217, 37-43. [CrossRef]

26. Andriani, H.; Kosasih, R.I.; Putri, S.; Kuo, H.W. Effects of changes in smoking status on blood pressure among adult males and females in Indonesia: A 15-year population-based cohort study. BMJ Open 2020, 10, e038021. [CrossRef]

27. Goette, A.; Lendeckel, U.; Kuchenbecker, A.; Bukowska, A.; Peters, B.; Klein, H.U.; Huth, C.; Röcken, C. Cigarette smoking induces atrial fibrosis in humans via nicotine. Heart 2007, 93, 1056-1063. [CrossRef]

28. Wang, H.; Shi, H.; Zhang, L.; Pourrier, M.; Yang, B.; Nattel, S.; Wang, Z. Nicotine is a potent blocker of the cardiac A-type K ${ }^{+}$ channels. Effects on cloned Kv4.3 channels and native transient outward current. Circulation 2000, 102, 1165-1171. [CrossRef]

29. Mahabadi, A.A.; Lehmann, N.; Sonneck, N.C.; Kälsch, H.; Bauer, M.; Kara, K.; Geisel, M.H.; Moebus, S.; Jöckel, K.H.; Erbel, R.; et al. Left atrial size quantification using non-contrast-enhanced cardiac computed tomography-Association with cardiovascular risk factors and gender-specific distribution in the general population: The Heinz Nixdorf Recall study. Acta Radiol. 2014, 55, 917-925. [CrossRef]

30. Jörgensen, K.; Müller, M.F.; Nel, J.; Upton, R.N.; Houltz, E.; Ricksten, S.E. Reduced intrathoracic blood volume and left and right ventricular dimensions in patients with severe emphysema: An MRI study. Chest 2007, 131, 1050-1057. [CrossRef] 
31. Tomita, H.; Yamashiro, T.; Matsuoka, S.; Matsushita, S.; Nakajima, Y. Correlation between heart size and emphysema in patients with chronic obstructive pulmonary disease: CT-based analysis using inspiratory and expiratory scans. Chronic Respir. Dis. 2018, 15, 272-278. [CrossRef] [PubMed]

32. Atas, H.; Kepez, A.; Atas, D.B.; Kanar, B.G.; Dervisova, R.; Kivrak, T.; Tigen, M.K. Effects of diabetes mellitus on left atrial volume and functions in normotensive patients without symptomatic cardiovascular disease. J. Diabetes Its Complicat. 2014, $28,858-862$. [CrossRef] [PubMed]

33. Hamza, M.; Mamdouh, A.; Ezzeldin, D.; Tawfik, A.; Nayel, A. Three-Dimensional Echocardiography in Evaluating LA Volumes and Functions in Diabetic Normotensive Patients without Symptomatic Cardiovascular Disease. Int. J. Vasc. Med. 2020, 2020, 5923702. [CrossRef] [PubMed]

34. Mahabadi, A.A.; Truong, Q.A.; Schlett, C.L.; Samy, B.; O’Donnell, C.J.; Fox, C.S.; Bamberg, F.; Hoffmann, U. Axial area and anteroposterior diameter as estimates of left atrial size using computed tomography of the chest: Comparison with 3-dimensional volume. J. Cardiovasc. Comput. Tomogr. 2010, 4, 49-54. [CrossRef]

35. Fredgart, M.H.; Carter-Storch, R.; Møller, J.E.; Øvrehus, K.A.; Pecini, R.; Dahl, J.S.; Gerke, O.; Alturkmany, R.A.; Brandes, A.; Lindholt, J.S.; et al. Measurement of left atrial volume by 2D and 3D non-contrast computed tomography compared with cardiac magnetic resonance imaging. J. Cardiovasc. Comput. Tomogr. 2018, 12, 316-319. [CrossRef]

36. Kühl, J.T.; Lønborg, J.; Fuchs, A.; Andersen, M.J.; Vejlstrup, N.; Kelbæk, H.; Engstrøm, T.; Møller, J.E.; Kofoed, K.F. Assessment of left atrial volume and function: A comparative study between echocardiography, magnetic resonance imaging and multi slice computed tomography. Int. J. Cardiovasc. Imaging 2012, 28, 1061-1071. [CrossRef] 